\title{
Boosting Lifelong Learning Through Digital Online Education:
}

\author{
Australian Perspectives and Practices
}

\author{
Jon Mason* \\ College of Education \\ Charles Darwin University \\ Darwin, Australia \\ *jon.mason@cdu.edu.au
}

\author{
Deb Carr \\ Think About Learning \\ Heathcote, Australia \\ deb@debcarr.com.au
}

\begin{abstract}
Informed by professional practice, practitioner research represents an important contribution to public discourse and research and development in many fields. This paper presents a practitioner-based overview of lifelong learning in Australia, its historical roots, development within public policy, relationship to various skills frameworks, the impact of emergent agendas such as Industry 4.0 and the recalibration of systems following the worldwide disruption of Covid-19. With disruption comes opportunity and a critical feature of lifelong learning in emerging futures is the role of digital technology in enabling it, and perhaps in transforming how lifelong learning will soon be understood.
\end{abstract}

Keywords-lifelong learning, skills frameworks, Australia, digital learning, Industry 4.0, Covid-19

\section{INTRODUCTION}

For several decades in Australia, as elsewhere in the world, lifelong learning has established itself as a pivotal construct in the development of public policy supporting education and training in all sectors - schooling, vocational education and training (VET), adult and community education (ACE), higher education (HE), as well as professional learning.

Origins of this term in Australia can be traced to the 1970s $[1,2]$. At that time, in the wake of adverse economic conditions triggered by the worldwide oil crisis, competitiveness of the workforce became a focus for public policy together with concern for achieving a better alignment between continuing education and work, through improving requisite skills that continue to be relevant for changing workforce needs. This represents a crucial moment in the history of Australian education and training because it was when the completion age of schooling was increased and anyone wishing to take on a work- based apprenticeship was encouraged to also complete their schooling [3].

Lifelong learning terminology, however, has often been qualified by other (sometimes ambiguous) terms such as the learning society, the knowledge society or the $21^{\text {st }}$ century skills agenda, and has not always had the expected impact or desired results [4,5]. Moreover, the UNESCO Institute for Lifelong Learning (UIL) board chairperson this year admitted many countries around the world have struggled with the complexity of implementing lifelong learning beyond conceptual thinking [6]. Despite being a conceptual strategic priority of governments on several occasions, without a longer term national policy combined and an accompanying evaluative framework, effectiveness of lifelong learning in Australia remains ambiguous. Thus, analyses four relatively detailed assessments of the effectiveness of lifelong learning policy in Australia to judge it as a national lack of vision and leadership with pockets of state and territory success. Added to this, expert practitioners in the adult basic education community report there is excessive focus on learning for work neglecting other domains such as learning for citizenship and financial and health well-being. The success or failure of policy, however, is contextual and contested. What is significant for this paper is that the terminology persists, whether as a core construct or as a passing descriptor.

With two decades of the twenty-first century concluding, a key aspect of lifelong learning in policy formulation has persisted in various expressions of skills that are fundamental to learning, with primarily a 'learning for employment' focus. Both education and training are now perceived to be parts of a lifelong learning process that enables individuals to take their places in a skilled and changing labour force, to lead fulfilling lives and to become active members of the community [7]. This is also articulated in more global perspectives [8]. Notably, the ACE sector warns [9] the absence of a national lifelong learning policy has manifested as too much of a 'skills' agenda neglecting to recognize the importance of empowering learning agility; that is, helping people to manage changing roles at work, in families and communities.

Thus, in the F-10 Australian curriculum, this is expressed as the 'general capabilities' and is one of three foundations of the curriculum. In the vocational sector, skills are expressed as the entire competency-based curriculum and design is increasingly intricated with explicit knowledge outcomes. 


\section{METHODS}

\section{A. Context}

As practitioners located in different fields of professional practice (higher education, vocational education and training (VET) and adult community education (ACE) the terminology lifelong learning represents nuanced meaning. Thus, when initiating this study, we felt it important to document our own understandings as a significant first step. We know that terminology matters and that it often needs to be defined to be fit for purpose - this is certainly the case where competencies and achievement standards are precisely defined. Thus, while lifelong learning is now more routinely associated with the VET and ACE sectors, we can also identify its use in the schooling and higher education sectors. This broad interpretation in both compulsory and post- compulsory contexts is how we use this term. Key attributes are identified as personal learning agency in changing environments through being self-directed and self-regulated, while socially shaped by a diversity of contexts throughout life.

\section{B. Research Question}

In identifying the dynamics shaping lifelong learning in Australia while considering the impact of Covid-19, we set out to address the question:

In what ways can digital technologies be effective in stimulating lifelong learning for employment within the contemporary context of Australia's skills development frameworks and immediate crisis of Covid-19?

\section{Research Design}

As practitioner research, this paper represents a synthesis of contemporary literature and open data that spans both research articles and public policy - specifically relevant to lifelong learning in Australia and informed by global perspectives. As such, it is a form of action research. In validating our own understandings, it also draws on expert input from the vocational education and training sector within Australia which was informed by the Delphi approach to developing industrybased forecasts [10].

\section{FINDINGS AND DISCUSSION}

\section{A. UNESCO's Lifelong Learning Pillars Enacted in} Australia's Three Post-Compulsory Education Sectors

In recognition of the global articulation and adoption of skills-focused frameworks we draw comparisons with a view to identifying learner needs that are now emerging as somewhat urgent among both mainstream and vulnerable cohorts arising from Covid-19.

Australia enjoys strong systems for lifelong learning that enable activation in all three post- compulsory education sectors, Higher Education, VET and ACE. The three forwardlooking pillars that enable implementation of lifelong learning are articulated recently by Daniel Bark [6]:
- Recognition of the multitudes of changes in the learning domains that put pressure on modern- day citizens such as learning for work, citizenship, health and financial well-being

- Recognition that learning occurs in a multitude of sites such as in school, community, workplace, family, neighbourhoods, online, libraries, peer-to-peer and formal education institutions

- Systemic approach to recognise informal and nonformal learning with credentials inside the formal education and training credentialing system

Australian's ACE and VET sectors combined, recognise learning pressures in multiple domains. The ACE sector is publicly funded to provide formal, informal and non-formal learning programs that enable adaption to changing economic and social landscape of all domains. The ACE sector reaches into community through place-based centres that reflect the diversity of local demographics. Programs are aimed at building confidence in learning and navigating systems whereby citizens are empowered in their learning and earning journeys. The VET sector focuses on the vocational domain of learning and empowers lifelong learners through strong articulation with higher education, a strong reskilling and upskilling agenda, strong connections with industry and little if any distinction between initial and continuing VET programs. Additionally, the VET sector encompasses many lower level qualifications that are designed as pathway certificates not directly associated to immediate work outcomes. General Education qualifications such as 'Course in Spoken and Written English' enable the VET sector to cater for new Australians to empower further learning and earning capability.

Recognition that learning occurs in a multitude of sites inherently frames the lifelong learner with agency for selfdirected autonomous learning, particularly for just-in-time online 'micro-learning'. It also highlights potential barriers to online learning such as connectivity, digital literacy for safe and critical learning and affordability of suitable devices. Recognition that learning happens in a multitude of sites is primarily manifested in a systemic way by local governments which are sometimes supported by state or federal policy frameworks such as 'The Future of Adult Community Education in Victoria' [11]. Progressive municipalities enable this pillar through long term lifelong learning strategies with two Australian councils; Melton and Wyndham being conferred into the UNESCO Global Learning City network.

The Australian Qualification Framework (AQF) sets a policy framework for the recognition of informal and nonformal learning through both the VET and higher education sectors. The VET sector implements this through a legislative framework whereby training organisations are mandated to offer recognition of prior learning (RPL) at enrolment. This system is mature and enables alternative pathways to VET qualifications for non-traditional learners. The implementation of RPL in Higher Education, however, lacks sector-wide consistency and transparency [12]. A recent review of the AQF 
recommended better use of RPL in both sectors as it "is crucial in an age of lifelong learning" [11].

\section{B. The Digital Revolution Driving Change}

For nearly three decades the digital revolution has been a major driver of change for education and training worldwide not only in the way that learning and training is accessed but in the consequent imperatives of skilling and reskilling [13-16]. Digital literacy skills are now integrated into all aspects of compulsory and post-compulsory education and training in Australia. In the Australian F-10 curriculum, such skills are highlighted as 'general capabilities'; in higher education, as 'graduate attributes'; while in VET and ACE, they have been recently specified as 'foundation skills' within the Digital Literacy Skills Framework (DLSF), which builds on the Australian Core Skills Framework (ACSF) [17].

Closely linked with the digital revolution is the emergence of 'Industry 4.0' as a policy agenda. While this terminology can be found earlier in the literature, its traction within global policy is most visible within the World Economic Forum [18]. This terminology immediately extends beyond the normalized ongoing disruptions of the digital revolution to signal farreaching transformation of industry itself. Of course, digital technologies as 'cyber-physical systems' will be what powers the transformation. One of the distinguishing features of the combined impact of the ongoing digital revolution and Industry 4.0 is that the notion of accelerated change in combined with disruption [19].

\section{Enabling Frameworks For Adults Continuing Education}

Flexibility and diversity are important features of the Australian VET system with a very wide range of accredited programs, providers and modes of study. Notably, there are few distinctions between initial and continuing VET programs; they are available to meet the needs of people of all ages. Figure 1 shows almost three quarter of VET enrolments in 2019 were 20 years and older with 41 per cent over 30 years.

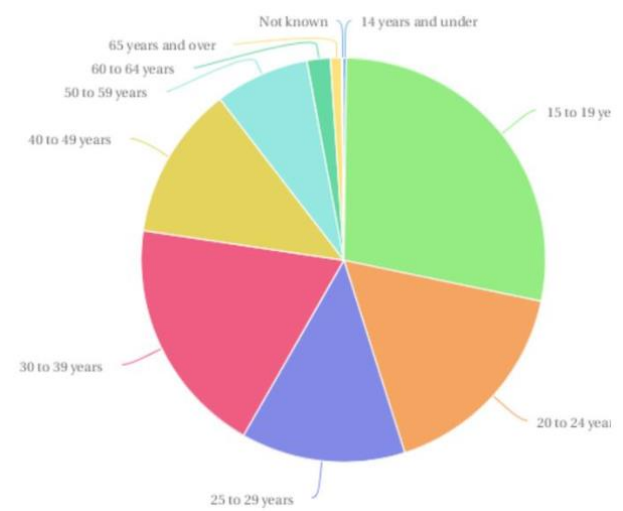

Fig. 1. Age distribution of Australian VET student enrolments in 2019 (Source: NCVER VOCSTATS)

Demand from adults continuing their education include those re-entering the workforce after absences, re-skilling for career transitions and upskilling for better jobs. Particularly helpful for these scenarios are short VET programs called 'skill sets' which are components of qualifications. Currently the Australian Industry and Skills Committee (AISC) is exploring opportunities these skill sets can provide for displaced workers, young people and women who have been particularly affected by the Covid-19 pandemic. VET programs can be delivered by schools, private and public training organisations, job centres, ACE providers and increasingly dual-sector universities. VET programs are funded by both governments and what is termed 'fee-for-service' which means individuals and organisations.

Australia has three primary enabling frameworks incorporated into VET and ACE programs that support lifelong learning accessibility and empowerment for work. These frameworks reflect underpinning generic skills necessary to thrive personally, in society and in work. These frameworks represent the vehicle by which the Australian and state and territory governments will reach the aspirational target set by the National Foundation Skills Strategy for Adults [20]: by 2022, at least two thirds of working age Australians will have the literacy and numeracy skills needed to take full advantage of opportunities afforded by Australia's new economy [21].

- Foundation Skills and Knowledge Framework (FSK)

- The Australian Core Skills Framework (ACSF)

- The Core Skills for Work Framework (CSfW)

The FSK framework sits inside the formal competencybased curriculum of the VET sector and as such is part of the AQF. FSK are a combination of learning, reading, writing, digital and speaking skills required by businesses at different levels of proficiency. The units of competency have multiple applications; as single units to augment vocational qualifications in response to learners' needs, as pathway qualifications into employment or education and as common language to explicitly describe the foundation skills embedded in VET competency- based curriculum. VET teacher training is supported with a nationally recognised skill set 'Address Foundation Skills in Vocational practice' as well as various state and territory initiatives such as South Australia's 'The Framework: Foundation Skills Professional Standards Framework June 2017'. The FSK framework was intended for both VET and ACE sectors to enable those currently in the workforce to overcome specific barriers hindering career progression - specifically literacy and numeracy [20].

The ACSF was released in 2008 as a tool to assist both specialist and non-specialist English language, literacy and numeracy practitioners profile an individual's performance in the five cores skills of learning, reading, writing, oral communication and numeracy. Digital literacy skills have been added to the framework in July 2020. The tool helps to profile learners core skills performance, map curricula, tailor learning and inform decisions such as funding and referrals in three diverse contexts, personal and community, workplace and employment and education and training. There is no curriculum within the ACSF. The framework is not aligned to the AQF 
however some industry sectors have chosen to map components of some units of competencies to the ACSF such as the units in the Aboriginal and Torres Strait Islander Health Worker Qualifications [22]. The framework is aligned with the FSK framework. This mature and widely used framework is readily recognised and respected by all levels of government and all education sectors and conspicuously addresses lifelong learning for all domains. This perhaps explains why the Australian Government has chosen this framework to embed digital literacy. Most recently, the ACSF is being used to assess individual needs for a national five- year Foundation Skills for Your Future Program aimed to develop Language, Literacy, Numeracy and Digital Literacy (LLND) skills for further education and training, to remain in employment or to change jobs. Notably, the program offers employers free workforce development in the areas of LLND. It is implemented utilising VET providers.

The addition of digital literacy skills to the ACSF is in response to a national review [23] whereby digital literacy skills renamed the core foundation skills LLND. Several national and international digital literacy frameworks were researched to inform the addition including the Australian Digital Inclusion Index [24], Irish Higher Education sector [25], OECD's Definition and Selection of Competencies, the United Kingdom's Digital and Information Literacy Framework [26,27] and UNESCO's Global Framework of Reference on Digital Literacy Skills for Indicator 4.4.2 [28].

The CSfW is a relatively new framework describing and articulating non-technical skills, knowledge and understandings that underpin successful participation in work. They can be accurately termed 'employability skills' and include problem solving, collaboration, self-management, communication and information technology skills, with five stages of performance from novice to expert. The framework is primarily for educators and learning designers involved in the development of training material, curriculum, standards and learning and assessment resources and strategies. However, arguably, the framework could also be manipulated to inform a matrix for the assessment of employability skills. There is little visibility of the use for this framework with no national focus on building VET or ACE workforces' capability to utilise.

\section{Growing Recognition for Vulnerable Cohorts}

Even with consideration of these enabling pillars and frameworks for lifelong learning access, there is growing recognition from our national, state and local governments to provide more consideration of communities experiencing social disadvantage, lack access to both technology and educational excellence [29], and are vulnerable to becoming unemployed and lack foundation skills for work, learning and life [11]. The recent review [23] of the national VET sector emphasised need for new supports learners in foundational language, literacy, numeracy and digital skills for second-chance learners. The higher education sector has noted substantial growth in the uptake of enabling courses, however there is question as to whether these courses factor in social and other essential services needed for success such as transport, health and welfare [30]. This had become critical in the backdrop of the rapidity of workplace change to support workers reskilling and upskilling every six years to maintain skill relevancy [31].

It is feared the Covid-19 pandemic may have exacerbated this divide with unprecedented numbers of displaced workers, older workers, women and regional workers having to consider and skill for career transitions [32]. The divide is fuelled by lack of digital ability on behalf of new learners and learning practitioners.

Thus, the remaining part of this paper underscores digital literacy as a key challenge for learners and describes some emerging practice that aims to optimise the emergency response for improved lifelong learning outcomes.

\section{E. Challenges for Adults Continuing Education in Online Environments in Australia}

Challenges for adults engaging in online education are not insignificant, especially in the context of those already experiencing barriers to education. Garland [33] frames these challenges as situational, institutional, dispositional and epistemological barriers.

Situational factors particularly impacting on adults continuing education in Australia are Internet affordability and lack of digital literacy [34], Internet access for remote locations [35] and hardware affordability. These challenges are highlighted in the current climate of Covid-19 restrictions. Community learning centres in Victoria report that learners have very limited access to devices in their homes whereby there may only be one device and the male may dominate use of that device. Additionally, digital literacy is wrongly assumed of these learners because they know how to use a Smart Phone, but they do not know how to use computers, send emails, upload documents and write documents (Interviewee 1).

Education institutions are behind contemporary learning culture of individuals and corporations [6]. Learners are preferencing online learning in their personal and work lives, they are a step ahead of education institutions. Cox and Prestige [36] found institutional challenges reduce opportunities for teachers to enact student-centred practice. Challenges include workload, sizes of classes, compliance with competency-based curriculum and the discipline being taught. Additionally, the way institutions transition to remote learning can transpire as a challenge particularly if there is no recognition of remote delivery as pedagogy in and on itself. Educators are constantly frustrated with ill-equipped systems whereby traditional content has just been 'put online' without re-designing it to reflect digital learning pedagogy [37].

Dispositional challenges apply to both practitioners and learners and describe the 'mindset' of users. Educator 'belief in online education' largely influences enactment of online education in the VET sector [36]. For adult learners, trust in online modes frequently manifests as a challenge [37], the degree of comfort for learners is a critical precondition for its 
success [38] and ACE sector learners have a preference for face-to- face delivery [39].

\section{F. Examples of Good Practice in Emergency Context}

1) Covid-19 a stimulus activating remote teaching: Whilst Australia's education policy environment has prioritised workforce development of adult learning educators towards utility of technology for learning beyond minimum levels of competency for a number of years now [38] there was reluctance and growth in capability, capacity and confidence has been slow. A study in 2016 [37] found the VET workforce had not yet embraced technological advancement as an opportunity to enrich learning environments, promote engagement facilitate deeper learning and improve workplace readiness. Covid-19 has brought immediacy to facing online education challenges - forcing institutions to adapt, be agile or downsize. The shift to online has moved more rapidly this year than ever before and unprecedented numbers of educators are currently navigating new online teaching contexts (Interviewee 4).

Community-based learning centres not transitioning to online solutions, where lock-down restrictions still inhibit gatherings, have closed their doors waiting for restrictions to ease leaving community members isolated and learning programs interrupted. Some, however, are offering innovative ways to support digital literacy for learners to continue to access their courses online such as hand delivering 'mail-outs' with screen prints and instructions on how to get online. One centre reported young learners teaching older educators a gaming application so the group could maintain connectivity during Covid-19 restrictions (Interviewee 1).

Australian private and public training organisations are not critically underprepared, and many are on mature pathways for remote delivery. A Victorian program working with disengaged young people has provided laptops and peripherals so that engagement is not disrupted with early indications of improved participation compared to fully face-to-face delivery modes (Interviewee 2). Apprenticeship models have been particularly hard hit as existing learners' work-based learning and assessment is disrupted and commencements have decreased [40]. PEER Training developed their capability for remote training of apprentices two years ago and rapidly executed their interactive and immersive system as the pandemic unfolded to ensure no extension of training would be required for current learners [41]. TAFE Queensland have had a whole team dedicated to online education for the past five years. The current crisis manifests as an opportunity to improve practice beyond technical skills to long-term pedagogical thinking for online teaching (Interviewee 4).

When institutional context supports online teaching, enactment is more likely [36]. Institutions are restructuring systems to support educators' transition to remote teaching. Victorian institutions are resourcing wrap-around supports via phone, online self-help and instructions in-language for learners to engage in digital environments. Institutional-wide feedback loops from learners and teachers are enabling rapid improvements to remote teaching implementation and preenrolment interviews are profiling learners for aptitude of online education. Institutions are reviewing their online teacher hiring, training and management practices to better understand online education as more than simply a different mode of delivery [36].

2) Evolving online teaching and learning pedagogy beyond technical expertise: The opportunity and challenge emerging from Covid-19 is to improve online education to become more than an alternative option of delivery, to a pedagogical approach in itself. Online pedagogy considers the complex interrelatedness of learning and the affordances of the environment. Online delivery (and access) promotes a transformational view of learning rather than a transmission view of learning [38]. "Too many trainers think that online should copy face-to-face, when in fact, it requires fundamentally different approaches, such as 10-minute chunked videos instead of long-winded live classes, and session structures need to be relaxed in open question, answer format rather than instructional" (Interviewee 4). Even skilled educators who are used to operating in online environments have been challenged bytransitions to wholly remote teaching. They report it is 'less warm' and they have had to think of new ways to 'connect' with learners (Interviewee 2). However, there is a danger that online will become 'wholesale' and lack drawing on other teaching and learning strategies such as group learning, use of external networks (Interviewee 3) and flipped classroom. This is a time to take stock, analyse and grab hold of the positives for lifelong learners this crisis may offer.

Online education has evolved to more than an improved opportunity for access as was the wider distribution focus of MOOCs. Technology now offers the ability for learning programs to create eco-systems of learning in more personalised ways [6]. Corporate Universities are the manifestation of corporations utilising digital technologies to activate more personalised learning and development ecosystems that focus not only on optimizing business achievements but helping shape personal career goals and mindsets of lifelong learners. Future VET learners will have higher levels of digital literacy and expectations that educators will use digital technology to provide the flexibility, convenience and more engaging learning experiences to which they have become accustomed [37]. Adult learners have expectations to learn at their own pace, in their own times, revisit material they are having difficulty understanding and collaborate on platforms they already use. Similarly, a program for disengaged young learners in Victoria that quickly transitioned to remote learning found learners were more engaged and less distracted as learning was more focused on them as individuals and less on group-learning. A laptop and dongle given to each young learner seemed to facilitate more individual accountable engagement as there was an increase feeling of ownership - that is, 'here's something that is mine' 
(Interviewee 3). The program manager believed a critical component of success was the continued individual connection with a facilitator which further facilitated personalised learning.

3) Educator roles are evolving - 'sage on the stage' being replaced by 'cyber-guide on the side': Online education in and of itself does not boost lifelong learning - the teacher's enactment of it is the critical linchpin for improved lifelong learning outcomes. The 'sage on the stage' is being replaced by the 'cyber-guide on the side' - although this narrative has been happening for some deacdes. The role of educators is evolving with "less emphasis on subject matter expertise and more on facilitating learning" [37]. Practitioners role has become more autonomous supportive than teacher led, it is critical they have the capacity to support learners now to learn more independently. A manager of a project to build online education capacity for eight public training organisations summarised a paradigm shift in educators' role to one that facilitates online learning empowerment rather than a 'sage from the stage' or teacher-led approach. The opportunity to boost lifelong learning utilising online education hinges critically on the capability of practitioners (Interviewee 2 ). The 'cyber-guide on the side' in the VET sector cater for learners who range in digital literacy for learning proficiency from novice to expert. Educators require digital-literacy- forlearning proficiency in the utilisation of technology and online pedagogy not only to conduct the practice of training and assessment but also to help improve digital learning confidence.

Within VET learners some cohorts such as migrants and older learners are less comfortable with using technology [37]. There is concern for vulnerable learners now forced to learn online, which has highlighted the importance of teaching practices on learners' mental health, wellbeing and success, in the context of learning and teaching online [42]. Even young people who have not had access to computer hardware and good Internet service are needing support. Educators for a program for disengaged young people are embracing online delivery. Learners are enthused, engaged and enjoying learning new technical skills as well as how to learn online. Educators report that easy, early wins for these new digital learners inherently scaffolds digital learning confidence (Interviewee 3 ). Educators have reported that learners have more instances of accountability and are becoming more autonomous and adaptive in managing their learning (Interviewee 3). Vulnerable learners are also being supported by institutionwide strategies such as wrap-around support via phone, online self-help and instructions in-language for learners to engage in digital environment, systemic feedback loops from learners and teachers on implementation of remote teaching and preenrolment interviews and profiling on aptitude for online education

The 'cyber-on-the-side' approach also caters for those digitally capable learners who have expectations technology utility will deliver personalised learning. Digital learning tools are emphasising collaboration, social learning and immersive learning. Developments in augmented reality, mobile learning and simulated learning environments continue to expand possibilities [37] and are particularly important for competency-based education on which the VET sector is founded. Thus, educators' role is to facilitate digital collaborative spaces and engaging strategies where deep learning and real connection can occur. A learner quoted, "if they [educators] know how to run the system, they can provide us with a better experience of learning" [37]. Educators need the technical know-how and agility to integrate new online pedagogy into numerous different platforms that align with learners' preferences and levels of comfort. Learners' engagement and peer support has been found to drop when educators do not make use of the digital platforms and channels in ongoing and meaningful ways [37].

VET educators are not all embracing this new role which transpires as less teacher-led and more student- centric. Reluctance is a complex mix of mindset, confidence and capability and also the level of institutional readiness and infrastructural support. Many educators feel completely out of their element [37]. Cox and Prestridge's [36] found educators' 'conception of teaching', their pedagogical beliefs transpire as a dispositional challenge for the enactment of online education. They found when pushed to online, these VET sector educators tended to default to more teacher-centric practice as opposed to learner-centric [36]. In the following anecdote, dispositional and institutional challenges are illustrated as successfully navigated to implement remote teaching and boost lifelong learning in several Australian public training organisations.

"Educators were refusing to record Zoom sessions for learners. Investigations into this behaviour found educators wanted to 'force' learners to attend live sessions for various reasons. There was an underlying pedagogical belief that repelled educator's willingness to embrace online teaching, particularly those with a 'sage on the stage' pedagogical belief. The manager reported educators were ultimately persuaded of the benefits of online teaching when shown technology that could self-mark online quizzes therein reducing their workloads" (Interviewee 2).

Recorded Zoom sessions, however, allow learners to learn in their own time and revisit material if they are struggling to understand. Immediate formative assessment feedback provides opportunity for learning design to be more personalised and responsive to learners' progress.

As with all change there is variance of willingness and competency for transitions to remote teaching. In the context of the Covid-19 crisis they can broadly be described as 'Eager Beavers', 'Struggling but Willing' and the 'Resisters'. Much is dependent on existing skills and the level of change required.

Dependents also include curriculum area of teaching and cohort's propensity for engaging online.

- Eager Beavers typically enjoy good Internet connectivity, adequate hardware and are confident in 
their digital literacy. They embrace quickly and feel they have benefited from learning new skills.

- Struggling but Willing are managing with peer support and rapid learning through webinars. There are reports of regional ACE centres helping each other improve capacity and capability (Interviewee 1).

- Resisters lack hardware, connectivity and a large gap in skills and knowledge. Some have little institutional support and are left to 'teach themselves'. They have opted out, have taken a break and will come back when it's more face to face.

\section{CONCLUSION}

Lifelong learning in Australia has been embedded in practice and referenced in public policy for several decades. It has carried with it both expectations and disappointment. Around the change of millennium, it had been referred to as a 'policy failure'. However, while it has had specific relevance to vocational, adult and continuing education, lifelong learning continues to find expression within wider discourse, probably due to the high utility of the term. Supported by various skills frameworks in Australia its most characteristic feature is that it speaks to the needs of the whole person and the environment in which they're located.

Prior to Covid-19 the contemporary era has been characterized in a multiplicity of ways and shaped by the economic forces of globalization together with advances in digital technologies. Preparation for the challenges of Industry 4.0 was already underway. In some ways, 'disruption' has now been normalised and so it is significant that the disruptions of Covid-19 are having unprecedented reach. As part of a widespread response, emergency remote education enabled by digital technologies is being deployed. In parallel, governments are scrambling to reformulate public policy that can sustain education and training, to ensure the underpinning infrastructure is resilient in facing the adverse economic and social circumstances. For this to be successful, digital skills will clearly underpin the next iteration of lifelong learning experiences for many. At the same time, conceiving lifelong learning primarily through skills- based frameworks will not be sufficient on their own. Sustainability and resilience apply to both the system infrastructure and the learner; moreover, these terms are primarily environmental, biological metaphors. In the Covid-19 era such descriptors are instrumental to learning that is lifelong and future-ready.

\section{REFERENCES}

[1] P. Karmel, "Schools in Australia: Report of the Interim Committee for the Australian Schools Commission, May 1973," 1973

[2] J. Chapman, J. Gaff, R. Toomey, and D. Aspin, "Policy on lifelong learning in Australia,” Int. J. Lifelong Educ., vol. 24, no. 2, pp. 99-122, 2005 .
[3] L. Yates, C. Collins, and K. O'Connor, Australia's curriculum dilemmas: State cultures and the big issues. Melbourne Univ. Publishing, 2011

[4] L. Watson, "Lifelong learning in Australia: a policy failure," Aust Assoc. Res. Educ., vol. 11, no. 11, 2004.

[5] L. Watson, Lifelong learning in Australia: Evaluations and Invesitgations Programme, Department of Education, Science and Technology, Australia. Department of Education, Science \& Training Canberra, 2003

[6] UNESCO Institute for Lifelong Learning (UILL), "The importance of Lifelong Learning in the 21st century," 2020

[7] Commonwealth of Australia, 2001 Year Book Australia. 2001.

[8] C. J. Dede and J. Richards, The 60-Year Curriculum: New Models for Lifelong Learning in the Digital Economy. Routledge, 2020.

[9] Adult Learning Australia (ALA), "A lifelong learning policy for Australia," 2018.

[10] S. Colton and T. Hatcher, "The Web-Based Delphi Research Technique as a Method for Content Validation in HRD and Adult Education Research.," Acad. Hum. Resour. Dev. Int. Conf., 2004.

[11] State Government of Victoria, "Ministerial Statement on The Future of Adult Community Education in Vicotira 2020-25," 2019

[12] P. Fox, "Adult Learning and Recognition of Prior Learning: The White Elephant in Australian Universities," Aust. J. Adult Learn., vol. 45, no. 3, pp. 352-370, 2005

[13] C.-Y. Park and J. Kim, "Education, Skill Training, and Lifelong Learning in the Era of Technological Revolution," Asian Dev. Bank Econ. Work. Pap. Ser., no. 606, 2020.

[14] A. Kanwar, K. Balasubramanian, and A. Carr, "Changing the TVET paradigm: New models for lifelong learning,” Int. J. Train. Res., vol. 17 no. sup1, pp. 54-68, 2019.

[15] L. M. Blaschke and S. Hase, "Heutagogy and digital media networks," Pacific J. Technol. Enhanc. Learn., vol. 1, no. 1, pp. 1-14, 2019.

[16] D. Zhang and J. F. Nunamaker, "Powering e-learning in the new millennium: an overview of e-learning and enabling technology," Inf. Syst. Front., vol. 5, no. 2, pp. 207-218, 2003.

[17] Australian Department of Education Skills and Employment (ADESE), "No Title," 2020.

[18] K. Schwab and N. Davis, Shaping the future of the fourth industrial revolution. Currency, 2018.

[19] T. L. Friedman, Thank you for being late: An optimist's guide to thriving in the age of accelerations (Version 2.0, With a New Afterword). Picador USA, 2017.

[20] Council of Australian Governments Standing Council on Tertiary Education Skills and Employment (SCOTESE), "National Foundation Skills Strategy for Adults," Brisbane, 2012. [Online]. Available: http://hdl.voced.edu.au/10707/223118.

[21] Australian Government Department of Education and Training, "Fact sheet: Foundation skills. Australian Government." [Online]. Available: https://www.myskills.gov.au/media/1777/back-to-basics-foundationskills.pdf.

[22] Community Services and health Industry Skills Council, "Foundation Skills Guide for Aboriginal and Torres Strait Islander health Worker Qualificaitons HLT Training pacage," 2015. [Online]. Available: https://vetnet.gov.au/Public Documents/HLT_Foundation_Skills_Gu ide.pdf.

[23] S. Joyce, "Strengthening skills: expert review of Australia's vocationa education and training system [Joyce review]." Department of the Prime Minister and Cabinet, Canberra, 2019

[24] A. Marshall, M. Dezuanni, J. Burgess, J. Thomas, and C. K. Wilson, "Australian farmers left behind in the digital economy-Insights from the Australian Digital Inclusion Index,” J. Rural Stud., vol. 80, pp. 195-210, 2020

[25] Irish Higher Education Sector, "All Abroad Ireland." [Online]. Available: https://www.allaboardhe.ie/. 
[26] K. Reedy and R. Goodfellow, "Digital and information literacy framework," Open Univ., 2012.

[27] D. S. Rychen and L. H. Salganik, "Definition and selection of competencies (DeSeCo): theoretical and conceptual foundations," Strateg. Pap. an Overarching Fram. Ref. a Coherent Assess. Res. Progr. Key Competencies-www. deseco. admin. ch, 2002.

[28] N. Law, D. Woo, J. de la Torre, and G. Wong, "A global framework of reference on digital literacy skills for indicator 4.4. 2," UNESCO Inst. Stat., 2018.

[29] D. Bradley, P. Noonan, H. Nugent, and B. Scales, "Review of Australian higher education," 2008.

[30] C. Ruddock, "Will Australia support a shift to lifelong learning?," 2019. [Online]. Available: https://www.openforum.com.au/will-australiasupport-a-shift-to-lifelong-learning/.

[31] D. Rumbens, C. Richardson, C. Lee, J. Mizrahi, and C. Roche, "The path to prosperity: Why the future of work is human," Sydney, Aust. Deloitte, 2019.

[32] Centre for Economic Development Australia (CEDA), "Rebuilding Australia's Workforce," 2020. [Online]. Available: https://www.ceda.com.au/Digital-hub/Videoarchive/2020/JUL/Rebuilding-Australia-s-workforce.

[33] M. R. Garland, "Student perceptions of the situational, institutional, dispositional and epistemological barriers to persistence," Distance Educ., vol. 14, no. 2, pp. 181-198, 1993.
[34] E. Rennie, J. Thomas, E. Hogan, A. Crouch, R. Gregory, and A. Wright, "Home internet in remote Indigenous communities," 2011.

[35] D. Cox and S. Prestridge, "Understanding fully online teaching in vocational education," Res. Pract. Technol. Enhanc. Learn., vol. 15, no. 1, pp. 1-22, 2020.

[36] A. Reeson, C. Mason, T. Sanderson, A. Bratanova, and S. Hajkowicz, "The VET era: Equipping Australia's workforce for the future digital economy," Rep. TAFE Queensland. Brisbane CSIRO, 2016.

[37] J. Slater, J.-I. Lindström, and G. Astbrink, "Australian Communications Consumer Action Network (ACCAN)," 2010.

[38] R. Brennan, M. McFadden, and E. Law, All That Glitters Is Not Gold: Online Delivery of Education and Training. Review of Research. ERIC, 2001.

[39] K. Bowman, "The value of ACE providers: A guide to the evidence base," Adult Learn. Aust. Canberra, 2006.

[40] National Centre for Vocational Education Research (NCVER), "Apprentices and trainees 2020: March quarter - Australia," 2020. [Online]. Available: https://www.ncver.edu.au/research-andstatistics/publications/all- publications/apprentices-and-trainees-2020.

[41] PEER Training, "Moving swiftly to digital tools to keep apprentices learning.," InDaily Adelaide Independent News, 2020.

[42] National Centre for Vocational Education Research (NCVER), "Focus on the impact of COVID-19 on education and training," 2020. [Online]. Available: https://www.voced.edu.au/focus-impact-covid-19-educationand-training. 